\title{
Congenital pressure gradients between main pulmonary artery and its primary branches
}

\author{
A. Barrillon, G. Havy, L. Scebat, J. Baragan, and A. Gerbaux \\ From Service de Cardiologie de l'Hôpital Boucicaut, Paris, France
}

I26 cases have been found with pressure gradients between the pulmonary artery trunk and its branches in the course of 594 diagnostic cardiac catheterizations. They occurred either alone: 16 cases (group I) or more often combined with congenital heart disease: IIO cases (group 2), about half of which were atrial septal defect. Angiographic findings and pressure gradients were correlated in 33 cases. A minor gradient across the junction of the main pulmonary artery with one of the branch pulmonary arteries was frequently present in patients with no angiographic evidence of branch stenosis. These pressure gradients corresponded with pictures of either hypoplasia or localized narrowing of the pulmonary artery branches only when the pressure difference amounted to or exceeded $15 \mathrm{mmHg}$, in those cases with absent or moderate shunting. This was supported by the finding that the rate of the pressure rise decreased by at least 50 per cent in the low pressure area.

During cardiac catheterization we often found a pressure difference between main and branch pulmonary arteries. The present study aims at assessing whether the finding of a lower pressure in the pulmonary artery branches than in the trunk always corresponds to organic stenosis.

\section{Methods and results}

In the course of 2433 consecutive catheterizations for congenital heart disease performed in Io years at the Boucicaut Hospital, a continuous withdrawai curve from the pulmonary capillary to the main pulmonary artery (PA) was obtained in 594 cases. A systolic pressure gradient was demonstrated in 126 cases $(22 \%$ of the withdrawal curves). These 126 cases concerned 53 male and 73 female patients whose age averaged 14.5 years (range 3.5 to 66 years). The patients were divided into two groups according to whether this pressure gradient was a lone anomaly (group 1 : 16 cases) or combined with other congenital cardiovascular lesions (group 2: I IO cases).

\section{Group I}

Pulmonary artery pressure (Table I)

A bilateral pressure gradient was found in the 12 cases in which both pulmonary artery branches were explored. In 4 cases, the right branch only was catheterized. The systolic pressure was lower in one or both pulmonary artery branches than the main pulmonary artery by an average of $14 \mathrm{mmHg}$ (range 5 to $90 \mathrm{mmHg}$ ). The systolic pulmonary artery pres-

TABLE I Systolic and diastolic pulmonary artery pressures (mmHg) in I6 patients of group I (without combined cardiac anomaly)

\begin{tabular}{|c|c|c|c|c|}
\hline $\begin{array}{l}\text { Case } \\
\text { No. }\end{array}$ & $\begin{array}{l}\text { Main } \\
\text { pulmonary } \\
\text { artery }\end{array}$ & $\begin{array}{l}\text { Left } \\
\text { pulmonary } \\
\text { artery }\end{array}$ & $\begin{array}{l}\text { Right } \\
\text { pulmonary } \\
\text { artery }\end{array}$ & Angiogram \\
\hline I & $20 / 8$ & $18 / 10$ & $15 / 8$ & Normal \\
\hline 2 & $25 / 8$ & - & $20 / 8$ & Normal \\
\hline 3 & $27 / 8$ & $22 / 6$ & $22 / 6$ & \\
\hline 4 & $15 / 5$ & - & $10 / 5$ & \\
\hline 5 & $24 / 8$ & - & $17 / 8$ & \\
\hline 6 & $28 / 7$ & $21 / 7$ & $21 / 7$ & \\
\hline 7 & $23 / 8$ & $15 / 8$ & $17 / 8$ & \\
\hline 8 & $25 / 5$ & $16 / 5$ & $16 / 5$ & \\
\hline 9 & $27 / 9$ & $18 / 9$ & $18 / 9$ & \\
\hline I0 & $27 / 7$ & $18 / 5$ & $18 / 5$ & \\
\hline I I & $27 / 7$ & $21 / 7$ & $15 / 5$ & \\
\hline I2 & $24 / 6$ & $\mathrm{II} / 4$ & $15 / 6$ & \\
\hline 13 & $35 / 10$ & $18 / 10$ & $18 / 10$ & $\begin{array}{l}\text { Stenosis of both } \\
\text { pulmonary ar- } \\
\text { tery branches }\end{array}$ \\
\hline I4 & $29 / 8$ & - & $11 / 4$ & \\
\hline 15 & $35 / 8$ & $15 / 8$ & $\mathrm{I} 1 / 8$ & $\begin{array}{l}\text { Multiple stenoses } \\
\text { on both pul- } \\
\text { monary artery } \\
\text { branches }\end{array}$ \\
\hline I6 & $100 / 5$ & $10 / 5$ & $20 / 5$ & $\begin{array}{l}\text { Left pulmonary } \\
\text { artery branch } \\
\text { hypoplasia }\end{array}$ \\
\hline
\end{tabular}


sure was within normal limits in 13 cases, moderately increased from 30 to $50 \mathrm{mmHg}$ in 2 , and much increased to $100 \mathrm{mmHg}$ in I case. In I case only was the 'pseudoventricular' pattern found in the main pulmonary artery pressure curve. The speed of the pressure rise on either side of the pulmonary artery branch gradient was measured in 14 of the 16 cases and expressed in $\mathrm{mmHg}$ per second. A 50 per cent or more diminution of the rate of pressure rise of the pulmonary artery branch as compared with that of the main pulmonary artery was found in 6 cases. In 8 cases, the rate of rise was diminished by less than 50 per cent.

\section{Standard $x$-ray signs}

The diameter of the pulmonary artery branches was often normal (I I cases), sometimes diminished (3 cases), and rarely increased ( 2 cases). The pulmonary vasculature was normal in 12 of 16 cases and no difference was observed between the two lung fields.

\section{Angiocardiography}

Right-sided angiocardiography carried out in 5 of 16 cases did not show any narrowing in 2 cases (Cases I and 2 with pressure gradients of $5 \mathrm{mmHg}$ ). Stenosis was demonstrated in 3 patients.

Case 13 Stenosis of both pulmonary artery branches (pressure gradient of $17 \mathrm{mmHg}$ on the right_and left sides).
Case I5 Multiple stenoses on both right and left pulmonary artery branches (pressure gradient of $24 \mathrm{mmHg}$ on the right side and $20 \mathrm{mmHg}$ on the left) (Fig. I).

Case I6 Pronounced dilatation, almost aneurysmal, of the trunk with a hypoplastic left branch and a normal right branch; the upper and middle lobar divisions of the latter had a diameter which diminished gradually in size (pressure gradient of 90 $\mathrm{mmHg}$ on the left side and $80 \mathrm{mmHg}$ on the right) (Fig. 2).

\section{Group 2}

I IO cases of pulmonary artery branch pressure gradient combined with other congenital cardiovascular disease.

\section{Pulmonary artery pressures (Table 2)}

Both pulmonary artery branches were explored in 33 cases and a bilateral pressure gradient was found in 25 cases, and a unilateral one, right-sided only, in 8 . In 77 cases one pulmonary artery branch only could be catheterized, which makes it impossible to provide information on bilateral pressure gradients. The pulmonary artery branch systolic pressure was lower by an average of II mmHg than the corresponding one of the main pulmonary artery (range 5 to $46 \mathrm{mmHg}$ ). The pulmonary artery systolic pressure was found to be within normal limits in 36

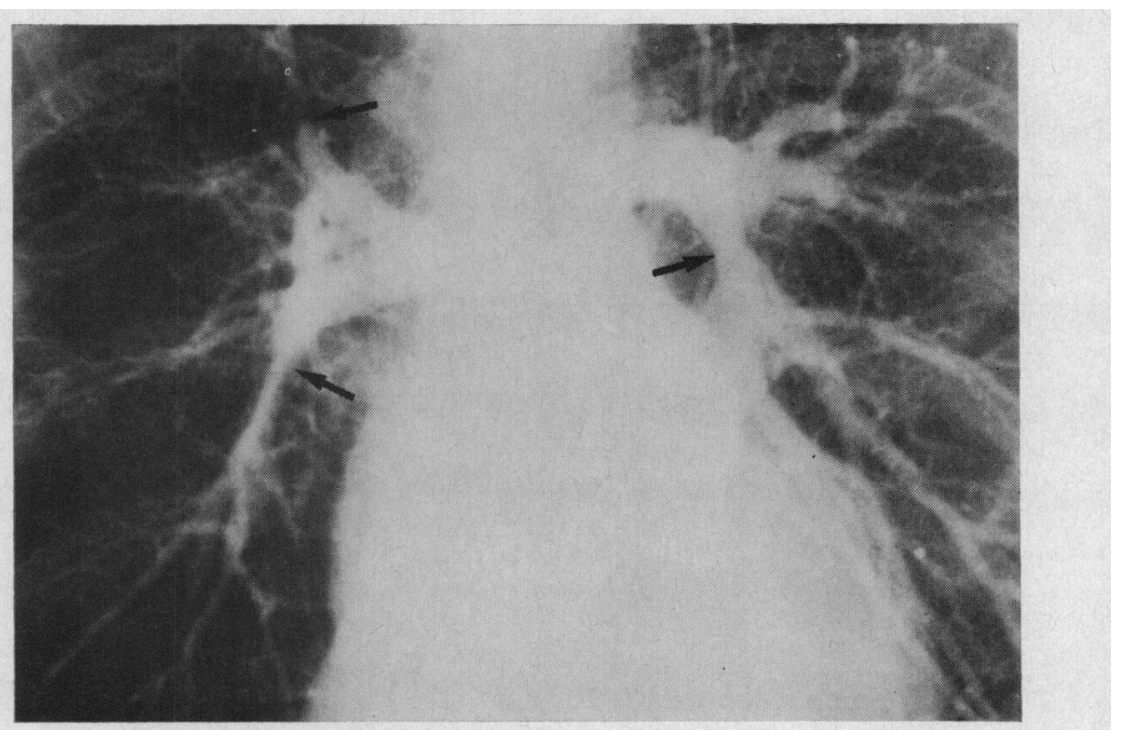

FIG. I A man aged 21 (Case I5 group I): multiple stenoses on both right and left pulmonary artery branches. Pressure gradients $24 \mathrm{mmHg}$ on the right side and $20 \mathrm{mmHg}$ on the left. 


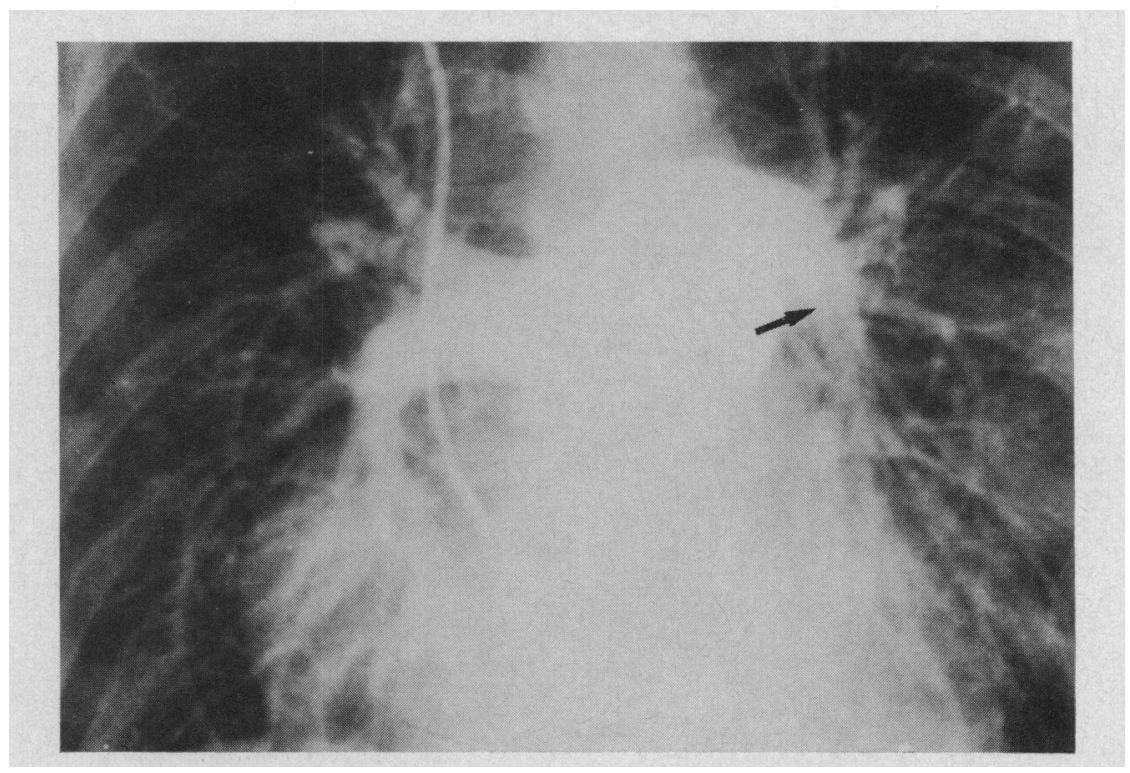

FIG. 2 A girl aged 20 (Case I6 group I): pronounced, almost aneurysmal, dilatation, of the main pulmonary artery with a hypoplastic left branch and a normal right branch. Pressure gradient of $90 \mathrm{mmHg}$ on the left and $80 \mathrm{mmHg}$ on the right side.

TABLE 2 Average of systolic pulmonary artery pressures $(\mathrm{mmHg})$ in 1 IO cases of group 2 (with combined cardiac anomalies): in brackets number of cases on which average was computed

\begin{tabular}{|c|c|c|c|c|}
\hline $\begin{array}{l}\text { Associated } \\
\text { anomaly }\end{array}$ & $\begin{array}{l}\text { No. } \\
\text { of } \\
\text { cases }\end{array}$ & $\begin{array}{l}\text { Main } \\
\text { pulmonary } \\
\text { artery }\end{array}$ & $\begin{array}{l}\text { Left } \\
\text { pulmonary } \\
\text { artery }\end{array}$ & $\begin{array}{l}\text { Right } \\
\text { pulmonary } \\
\text { artery }\end{array}$ \\
\hline $\begin{array}{l}\text { Atrial septal } \\
\text { defect }\end{array}$ & 59 & $3 I$ & 25 (I5) & $20(58)$ \\
\hline $\begin{array}{l}\text { Ventricular } \\
\text { septal defect }\end{array}$ & 12 & 26 & $12(2)$ & 20 (10) \\
\hline $\begin{array}{l}\text { Pulmonary } \\
\text { valvar } \\
\text { stenosis }\end{array}$ & 17 & 37 & 24 (10) & $20(16)$ \\
\hline $\begin{array}{l}\text { Obstructive } \\
\text { cardiomyopathy }\end{array}$ & 6 & $3 \mathrm{I}$ & $22(I)$ & $22(5)$ \\
\hline $\begin{array}{l}\text { Coarctation of } \\
\text { aorta }\end{array}$ & 4 & 32 & 24 (I) & 2 I (4) \\
\hline $\begin{array}{l}\text { Partial anomalous } \\
\text { pulmonary } \\
\text { drainage }\end{array}$ & 4 & 35 & $30(2)$ & $22(4)$ \\
\hline $\begin{array}{l}\text { Persistent atrio- } \\
\text { ventricular canal }\end{array}$ & 3 & 33 & $24(I)$ & 21（3） \\
\hline $\begin{array}{l}\text { Tetralogy of } \\
\text { Fallot }\end{array}$ & $\mathbf{I}$ & 35 & - & 25 \\
\hline $\begin{array}{l}\text { Supravalvar } \\
\text { aortic stenosis }\end{array}$ & $\mathbf{I}$ & 25 & - & 20 \\
\hline $\begin{array}{l}\text { Communication } \\
\text { between right } \\
\text { atrium and left } \\
\text { ventricle }\end{array}$ & $\mathbf{I}$ & 30 & - & 18 \\
\hline Single ventricle & $\mathbf{I}$ & 45 & 29 & 24 \\
\hline Persistent ductus & $\mathbf{I}$ & 33 & - & I I \\
\hline
\end{tabular}

$\star$ With superadded ventricular defect in 5 cases, atrial septal defect in 2 , atrioventricular canal in I case. cases; moderately increased from 30 to $50 \mathrm{mmHg}$ in 66 cases, and much increased above $50 \mathrm{mmHg}$ in 8 cases only. The pressure curves of the trunk demonstrated a 'pseudoventricular' pattern in 48 of the I ro cases of this group. A 50 per cent or more diminution of the rate of pressure rise in the low pressure area in relation to that of the main pulmonary artery was found in 24 of the roo cases of this group in which it was measured; in all other cases, this was less than 50 per cent. For each case the pulmonary artery output, the systemic output, and the pulmonary artery output/systemic output ratio was calculated.

\section{$\boldsymbol{X}$-rays}

These frequently showed (6o cases) increased shadows of the pulmonary artery branches with congestion of both lung fields, easily accounted for by the presence of a shunt. In 77 cases, there was a difference in the vasculature between the two lung fields; in 6 cases decreased vascular shadows were noted on the same side as the gradient, but in 8 cases, larger vascular shadows were found on the same side as the pressure gradient; finally in 3 cases there were asymmetrical vascular shadows when the pressure gradients were identical on both sides.

\section{Pulmonary angiogram}

This was normal in 17 of the 28 cases. In I I cases the pulmonary artery branches were abnormal: 
there was hypoplasia of the pulmonary artery tree in 5 cases, coarctation of both branches in 2 cases, coarctation of the right branch in 2 cases, hypoplasia of the left branch with stenosis of the division branches and stenosis with post-stenotic dilatation of the right branch in I case, and coarctation of both main pulmonary artery branches with narrowed distal branches in I case.

\section{Surgical findings}

Operation was attempted in 2 cases of pulmonary artery branch stenosis; in one case both branch stenoses were dilated with a dilatator; in one case a 'teflon' patch was inserted on the intermediate trunk of the right branch.

\section{Pathological findings}

One case aged 4 died on the day of catheterization, which showed an ostium primum with a single ventricle of the right type. There were no definite coarctations of the pulmonary artery branches but rather a hypoplasia of the distal branches which were thin, soft, and transparent, very different in texture from that of the main pulmonary artery. Yet on catheterization the systolic pressures were 45 $\mathrm{mmHg}$ in the pulmonary artery trunk, $29 \mathrm{mmHg}$ 


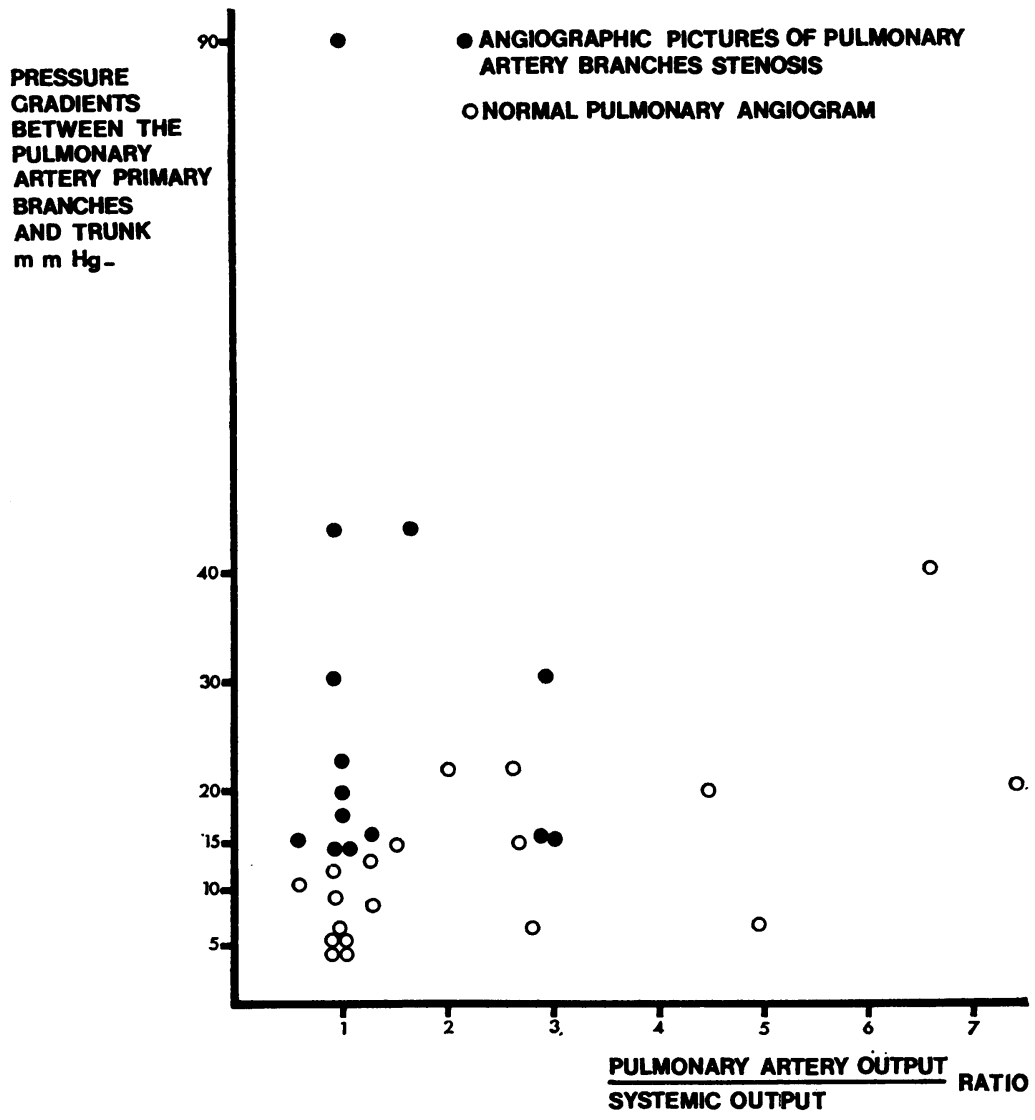

FIG. 4 Correlation between the magnitude of the pressure gradient (ordinate) and the pulmonary artery output/systemic output ratio (abscissa) in the 33 cases with normal (open circles) or abnormal (closed circles) angiograms. Note that most cases with pulmonary artery branch stenosis are included in an area with a pulmonary artery output/systemic output ratio below 2 and at or above the level $15 \mathrm{mmHg}$ pressure gradient.

in the left branch, and $24 \mathrm{mmHg}$ in the right branch.

\section{Discussion}

Pressure gradients between the branches and the trunk of the pulmonary artery have been recorded with increasing frequency during catheterization for congenital heart disease (Eldridge, Selzer, and Hultgren, 1957; Bell et al., 1962; Franch and Gay, 1963; Gasul, Arcilla, and Lev, I966; Latour et al., I970). Axillary transmission of the systolic murmur, found in this series in 59 of 65 cases in which it was looked for, was the most reliable physical sign (Bouvrain, Bourthoumieux, and Nezry, I96I ; Oram, Pattinson, and Davies, 1964; Perloff and Lebauer, 1969). A difference in density between the two lung fields on the $x$-ray picture, obvious in only 17 of the 126 of this series, is an inconstant finding. From this, it is impossible to predict the site of a pressure gradient. Increased pulmonary vascular shadows were found on the same side as the pulmonary artery branch pressure gradient in II cases. Others (Gyllensward et al., 1957; Nadas, 1963; Fouron et al., 1967) have reported similar findings. According to Fouron et al. (1967) this change is related to age. Catheterization of the pulmonary circulation provides direct evidence of a pressure gradient in the pulmonary pathway. But selective angiography of the main pulmonary artery or the right ventricle is the only reliable procedure for demonstration of organic stenosis (Baum et al., 1964). A group of cases with an obstruction on the 
pulmonary artery pathway should be distinguished from a second group in which no such stenosis could be demonstrated.

Out of the 33 cases in which pulmonary angiography was carried out, I4 demonstrated a pulmonary artery branch hypoplasia (5 cases) or localized narrowing with coarctation of one or two branches (9 cases), a fact reported by Arvidsson, Karnell, and Moller as early as 1955 (Arvidsson et al., 196I). The alleged specificity of post-stenotic dilatation (Nadas, 1963) was not confirmed in this series. Two cases only were operated upon. This is possible when the stenosis is proximal (Baxter, Booth, and Sirak, I96I; McGoon and Kincaid, 1964) and desirable when the main pulmonary artery pressure is increased (Dubost, Cachera, and Vigano, 1967) (62 and $37 \mathrm{mmHg}$ in the cases operated on). The severity of obstruction to pulmonary blood flow does not increase with age (Eldredge et al., 1972). Necropsy is exceptional, as this anomaly is usually well tolerated. Performed once in this series, it showed an abnormal structure of the elastic wall responsible for a vessel wall thinning. Other lesions have been described as intimal hyperplasia of the main branches simulating atheromatous plaques (Oppenheimer, 1938; Esterly and Oppenheimer, 1967). The arguments in favour of organic pulmonary artery branch stenosis are as follows.

Clinical picture History of German measles in the mother combined with a reduced auditory acuity was found in 2 cases of this series, cataract was found in I further case (Oram et al., 1964; Esterly and Oppenheimer, 1967; Rowe and Mehrizi, 1970). Combined supravalvar aortic stenosis may be suspected by the peculiar facies and mental retardation with a history of hypercalcaemia (Beuren, Apitz, and Harmjanz, 1962; Bourassa and Campeau, 1963).

'Pseudoventricular' pattern of the main pulmonary artery pressure curve was thought by Agustsson et al. (1962) to be pathognomonic of bilateral pulmonary artery branch stenosis; the more pronounced, the tighter the stenosis. It is characterized by a rapid systolic rise followed by a diastolic fall to low early diastolic pressure, followed by a mid or late diastolic plateau. In this series, 16 of the 49 cases with this pattern had angiograms which demonstrated pulmonary artery stenosis in 9 cases only. In this series this pressure curve pattern was thus absent in cases with severe stenosis while it was recorded in cases with mild gradients but without angiographic evidence of stenosis. According to Delaney and Nadas (1964) and Nadas (1963) this should be considered a suggestive though unreliable sign.

Speed of pulmonary artery pressure rise on either side of the pressure gradient appears to be a better sign of organic stenosis of the pulmonary artery branches. Rios et al. (1969) have shown this pressure rise in a series of 17 cases to be 50 per cent slower in the post-stenotic area than in the proximal area. In the absence of organic stenosis, these speeds were identical on either side of the pressure gradient. This sign was found in the present series in 30 of I 26 cases. Of the 29 cases with angiogram, ${ }^{1}$ this sign coincided commonly with organic stenosis (IO of I5 cases). Conversely, stenosis was found only rarely (I of I4 cases) in the absence of this sign. This 50 per cent slowing of the post-stenotic speed of the pulmonary artery pressure rise seemed to be a reliable sign (Fig. 3) and deserves to be retained as a good indication of organic stenosis.

Magnitude of pressure gradient The presence of branch stenosis on the angiograms coincided with pressure gradients of $15 \mathrm{mmHg}$ or more, in the absence of shunt (group I). However, in the presence of left-to-right shunts, pressure gradients larger than I5 $\mathrm{mmHg}$ may be found in the absence of stenosis (Williams, Lange, and Hecht, 1957). In other words, a pressure gradient below $15 \mathrm{mmHg}$ is unlikely to be caused by stenosis, while in the cases in which it exceeds $15 \mathrm{mmHg}$ a true stenosis is a possibility which requires to be proved by an angiogram (Fig. 4).

In the remaining 19 cases $(58 \%)$ the angiograms did not reveal any stenosis. To account for the presence of pressure gradients in the absence of an angiographic picture of stenosis, three hypotheses may be put forward:

Increase of the pulmonary artery flow resulting from a left-to-right shunt (Deyrieux, Tartulier, and Tourniaire, 196I): On the one hand, pressure gradients have been found in heart diseases without shunts (group I), and on the other, when these pressure gradients occur in heart diseases with a left-to-right shunt (group 2), the latter is often mild (pulmonary artery output/systemic output ratio below 2) (Fig. 4). Surgical closure of the shunt resulted in abolition of the systolic murmur in only 21 of 55 cases. Finally, numerous cases with large left-to-right shunts never demonstrated such gradients.

Presence of mild stenosis invisible to angiography.Persistence or aggravation of physiological pressure differences between main and branch pulmonary arteries in infants (Danilowicz et al., 1972). Fouron et al. (1967) and Rowe and Mehrizi (1970) have demonstrated in the normal infant a pressure gradient of 3 to $7 \mathrm{mmHg}$ between the main pulmonary artery and its branches. Danilowicz et al. (1972) have shown the disappearance in infants of systolic

1 In 4 cases with angiograms, the speed of the pressure rise could not be measured. 
pressure differences of 6 to $45 \mathrm{mmHg}$. Increase of the pulmonary artery blood flow, especially in the presence of a left-to-right shunt, would result in elastic tissue changes, with consequent pressure gradients between the main and branch pulmonary arteries, with or without organic stenosis.

\section{References}

Agustsson, M. H., Arcilla, R. A., Gasul, B. M., Bicoff, J. P., Nassif, S. I., and Lendrum, B. L. (1962). The diagnoses of bilateral stenosis of the primary pulmonary artery branches based on characteristic pulmonary trunk pressure curves. Circulation, 26, 421.

Arvidsson, H., Carlsson, E., Hartmann, A., Tsifutis, A., and Crawford, C. (I96I). Supravalvular stenoses of the pulmonary arteries. Report of eleven cases. Acta Radiologica, 56, 466.

Arvidsson, H., Karnell, J., and Moller, T. (1955). Multiple stenosis of the pulmonary artery associated with pulmonary hypertension diagnosed by selective angiocardiography. Acta Radiologica, 44, 209.

Baum, D., Khoury, G. H., Ongley, P. A., Swan, H. J. C., and Kincaid, O. W. (1964). Congenital stenosis of the pulmonary artery branches. Circulation, 29, 680.

Baxter, C. F., Booth, R. W., and Sirak, H. D. (196r). Surgical correction of congenital stenosis of the right pulmonary artery accompanied by agenesis of the left pulmonary artery. Fournal of Thoracic and Cardiovascular Surgery, 4r, 796.

Bell, A. L. L., Jr., Kightlinger, B., Shimomura, S., and Krstulovic, V. (1962). Postvalvular pulmonary artery stenosis. Hemodynamic and radiographic definition (abstract). Circulation, 26, 685 .

Beuren, A. J., Apitz, J., and Harmjanz, D. (1962). Supravalvular aortic stenosis in association with mental retardation and a certain facial appearance. Circulation, 26, 1235.

Bourassa, M. G., and Campeau, L. (1963). Combined supravalvular aortic and pulmonic stenosis. Circulation, 28, 572.

Bouvrain, Y., Bourthoumieux, A., and Nezry, R. (I961). Souffles sytoliques à irradiations axillaires et rétrécissement des branches de l'artère pulmonaire. Archives des Maladies du Coeur et des Vaisseaux, 54, 999.

Danilowicz, D. A., Rudolph, A. M., Hoffman, J. I. E., and Heymann, M. (1972). Physiologic pressure differences between main and branch pulmonary arteries in infants. Circulation, 45, 410.

Delaney, T. B., and Nadas, A. S. (1964). Peripheral pulmonic stenosis. American fournal of Cardiology, 13, $45 \mathrm{I}$.

Deyrieux, F., Tartulier, M., and Tourniaire, A. (I96I). Sténose del'artère pulmonaire droite. Phonocardiographie endocavitaire et étude hémodynamique de 2 cas. Archives des Maladies du Coeur et des Vaisseaux, 54, 1004.

Dubost, Ch., Cachera, J. P., and Vigano, M. (1967). Sténose bilatérale des branches de l'artère pulmonaire. Correction chirurgicale. Annales de Chirurgie, 21, 45 I.
Eldredge, W. J., Tingelstad, J. B., Robertson, L. W., Mauck, H. P., and McCue, C. M. (1972). Observations on the natural history of pulmonary artery coarctations. Circulation, 45, 404.

Eldridge, F., Selzer, A., and Hultgren, H. (1957). Stenosis of a branch of the pulmonary artery, an additional cause of continuous murmurs over the chest. Circulation, 15, 865 .

Esterly, J. R., and Oppenheimer, E. H. (1967). Vascular lesions in infants with congenital rubella. Circulation, 36, 544 .

Fouron, J. C., Favreau-Ethier, M., Marion, P., and Davignon, A. (1967). Sténoses pulmonaires périphériques congénitales. Canadian Medical Association fournal, 96, 1084.

Franch, R. H., and Gay, B. B. (1963). Congenital stenosis of the pulmonary artery branches. American fournal of Medicine, 35, 512.

Gasul, B. M., Arcilla, R. A., and Lev, M. (1966). Heart Disease in Children, pp. 793-806. J. B. Lippincott, Philadelphia; Pitman, London.

Gyllensward, A., Lodin, H., Lundberg, A., and Möller, T. (1957). Congenital, multiple peripheral stenoses of the pulmonary artery. Pediatrics, 19, 399.

Latour, H., Puech, P., Grolleau-Raoux, R., and Balmes, P. (1970). Sténoses du tronc et des branches de l'artère pulmonaire. Actualités cardio-vasculaires médico-chirurgicales, 5ème série, 289 p. I63. Masson, Paris.

McGoon, D. C., and Kincaid, O. W. (1964). Stenosis of branches of the pulmonary artery; surgical repair. Medical Clinics of North America, 48, 1083.

Nadas, A. S. (1963). Pediatric Cardiology, pp. 669-675. W. B. Saunders, Philadelphia and London.

Oppenheimer, E. H. (1938). Partial atresia of the main branches of the pulmonary artery occurring in infancy and accompanied by calcification of the pulmonary artery and aorta. Bulletin of the fohns Hopkins Hospital, 63, 261.

Oram, S., Pattinson, N., and Davies, P. (1964). Post-valvular stenosis of the pulmonary artery and its branches. British Heart fournal, 26, 832.

Perloff, J. K., and Lebauer, E. J. (1969). Auscultatory and phonocardiographic manifestations of isolated stenosis of the pulmonary artery and its branches. British Heart fournal, 31, 314 .

Rios, J. C., Walsh, B. J., Massumi, R. A., Sims, A. J., and Ewy, G. A. (I969). Congenital pulmonary artery branch stenosis. American fournal of Cardiology, 24, 318.

Rowe, R. D., and Mehrizi, A. (1970). Cardiopathies Congénitales du Nouveau-né, p. 25 and p. 309. Masson, Paris.

Williams, C. B., Lange, R. L., and Hecht, H. H. (1957). Postvalvular stenosis of the pulmonary artery. Circulation, I6, 195.

Requests for reprints to Dr. A. Barrillon, Service de Cardiologie de l'Hôpital Boucicaut, 78 rue de la Convention, 75015 Paris, France. 